\title{
ETIOLOGY OF ACUTE PYELONEPHRITIS AND ANTIBACTERIAL RESISTANCE IN PEDIATRIC MALE AND FEMALE PATIENTS
}

\author{
Roberts Gobergs ${ }^{1,3}$, Ieva Kravale ${ }^{1,2}$, Elza Salputra ${ }^{4}$, Edīte Jeruma ${ }^{3}$ \\ ${ }^{1}$ Department of pathology, Riga Stradiņš University, Latvia \\ ${ }^{2}$ Vidzeme hospital, Latvia \\ ${ }^{3}$ Children Clinical University hospital, Latvia \\ ${ }^{4}$ Jurmala hospital, Latvia
}

Table 1. Number of male and female patients included in the study, with obtained urine culture and with positive urine culture and median age for both sexes.

\begin{tabular}{|l|l|l|l|}
\hline & Male & Female & $\mathrm{p}$ \\
\hline Number of patients, \% (n) & $29(221)$ & $71(546)$ & \\
\hline Age, months (IQR) & $5(2-18)$ & $49(12-103)$ & $\mathrm{p}<0.001$ \\
\hline Urine culture obtained, \% (n) & $71(157)$ & $58(317)$ & $\mathrm{p}=0.001$ \\
\hline Positive urine culture, \% (n) & $76(120)$ & $75(236)$ & $\mathrm{p}=0.735$ \\
\hline
\end{tabular}

Data are presented as median and IQR unless indicated otherwise by \% (n).

$\mathrm{IQR}$ - interquartile range, $\mathrm{n}$ - number of patients.

\section{Background and Aims}

Acute pyelonephritis (AP) is common in childhood and the choice of empiric therapy should be based on the local antibacterial resistance (AR), which might differ between sexes.

The aim of our study was to determine the most common etiological agents of $\mathrm{AP}$ and their $\mathrm{AR}$ in paediatric population.

\section{Method}

A retrospective study was performed to determine the differences between etiological agents of AP in male and female patients and their AR to cefuroxime, nitrofuran and cefotaxime. Extended-spectrum betalactamases (ESBL) producing agents were also analysed. Medical histories of 769 inpatients with diagnosis of AP or exacerbation of chronic pyelonephritis during a 4-year period (2013 - 2016) were studied.

\section{Results}

$29 \%(\mathrm{n}=221)$ of the patients were male. In $46 \%(\mathrm{n}=356)$ the diagnosis was confirmed with a positive urine culture (PUC) (table 1.). The isolated agents from PUCs were E. coli in $54 \%(\mathrm{n}=65)$ and $85 \%$ $(\mathrm{n}=201)$, other single agents in $22 \%(\mathrm{n}=26)$ and $9 \%(\mathrm{n}=20)$, and multiple agents in $24 \%(\mathrm{n}=29)$ and $6 \%(\mathrm{n}=15)$ male and female patients respectively, $\mathrm{p}<0,001$ (figure 1 . and 2.). AR to cefuroxime, nitrofuran and cefotaxime, when determined (table 2.), was $17 \%$ $(\mathrm{n}=12), 14 \%(\mathrm{n}=16)$ and $16 \%(\mathrm{n}=15)$ respectively in male patients and $4 \%(\mathrm{n}=6), 5 \%(\mathrm{n}=11)$ and $4 \%(\mathrm{n}=8)$ in female patients, $\mathrm{p}=0,002$ (for difference between sexes). ESBL production was determined in 294 PUCs and was positive in $14 \%(n=13)$ and $3 \%(n=6)$ of cases in male and female patients respectively, $\mathrm{p}<0,001$ (figure 3 .).

\section{Conclusion}

The aetiology of AP differs in male and female patients. The AR to cefuroxime, nitrofuran and cefotaxime is higher in males. ESBL producing agents are more common in males.

\section{Abbreviations}

$\mathrm{AP}$ - acute pyelonephritis

$\mathrm{AR}$ - antibacterial resistance

ESBL - extended spectrum beta- lactamase

IQR - interquartile range

PUC - positive urine culture

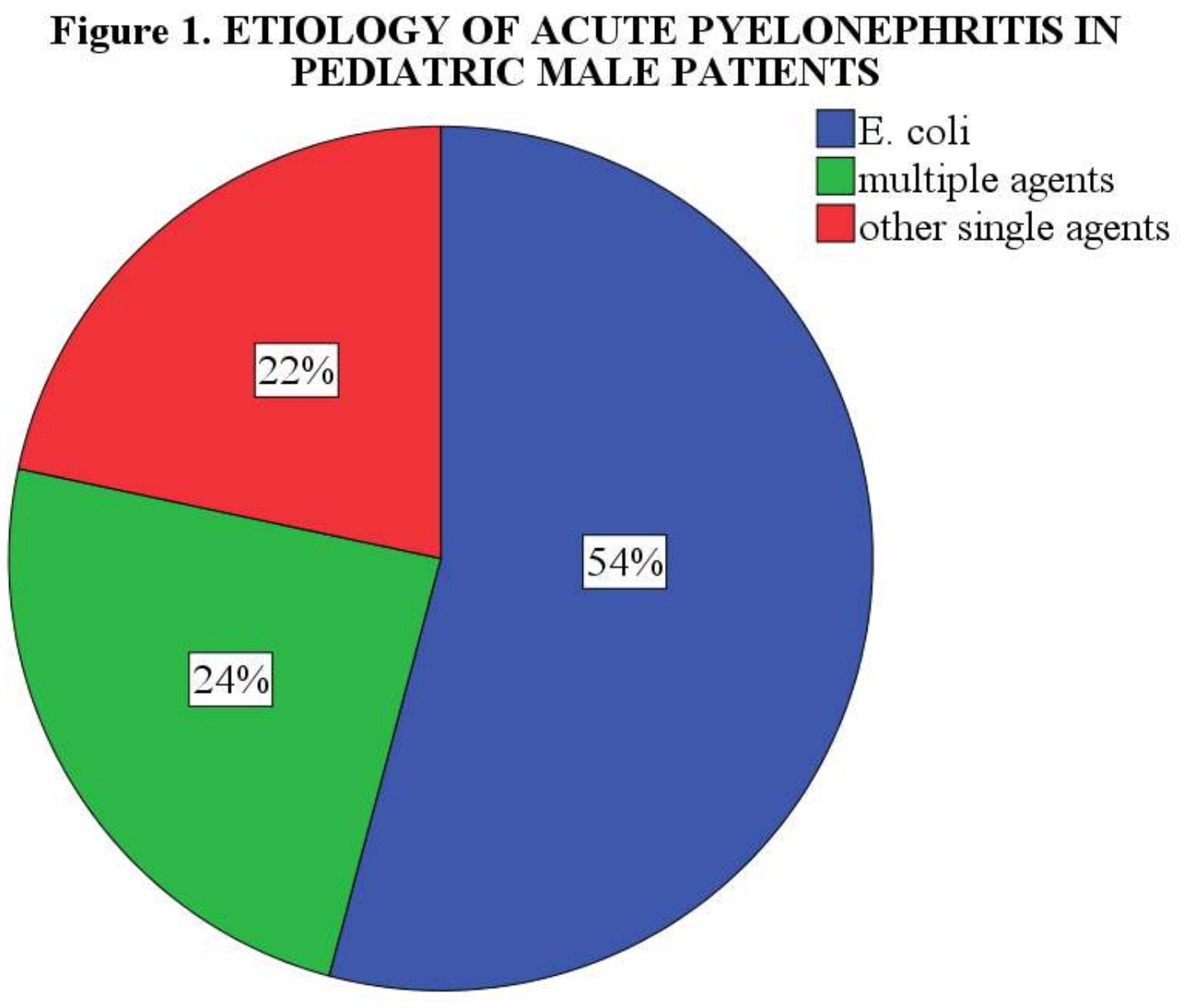

Figure 2. ETIOLOGY OF ACUTE PYELONEPHRITIS IN PEDIATRIC FEMALE PATIENTS

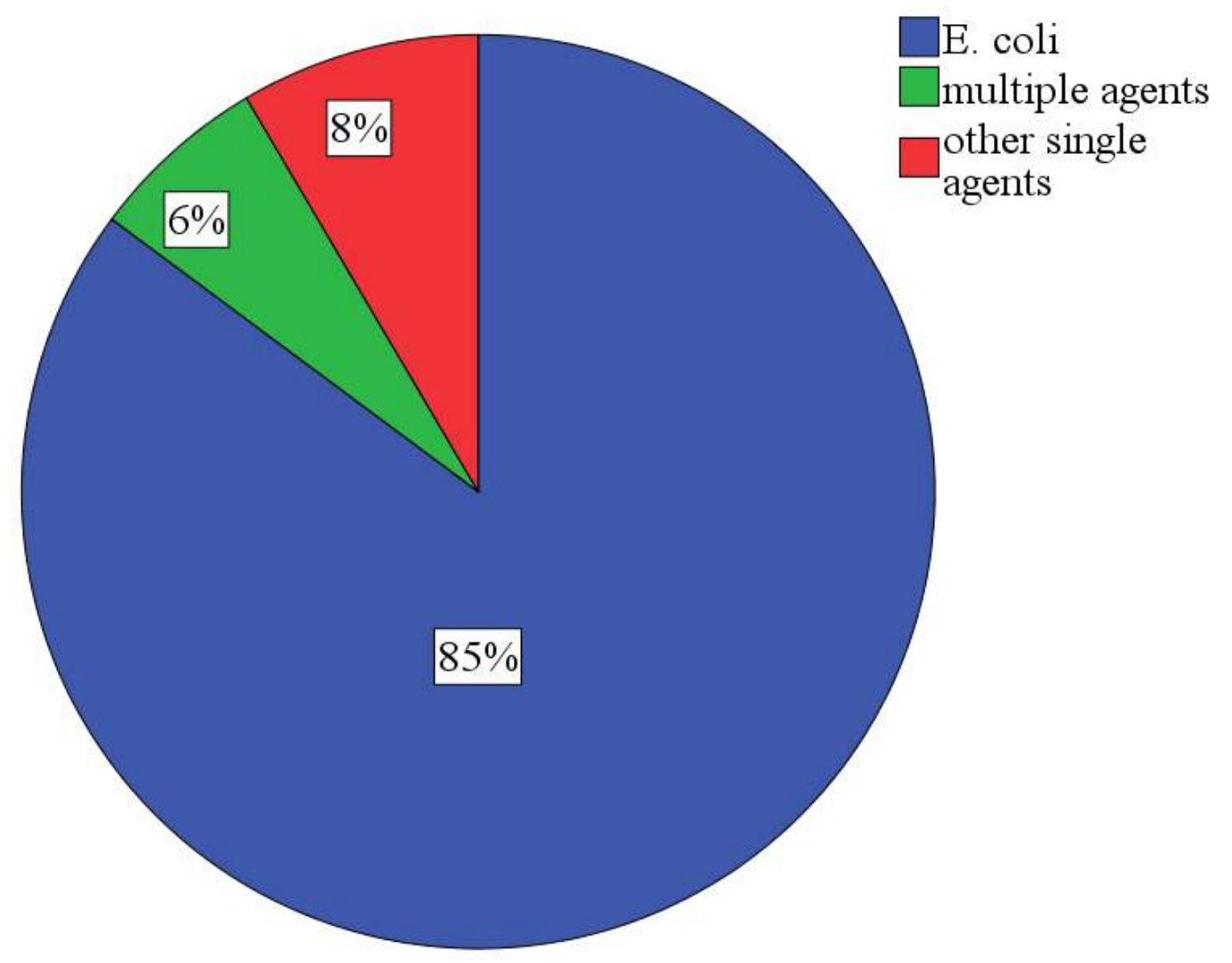

Figure 3. Antibacterial resistance to cefuroxime, nitrofuran and cefotaxime and ESBL production in male and female patients

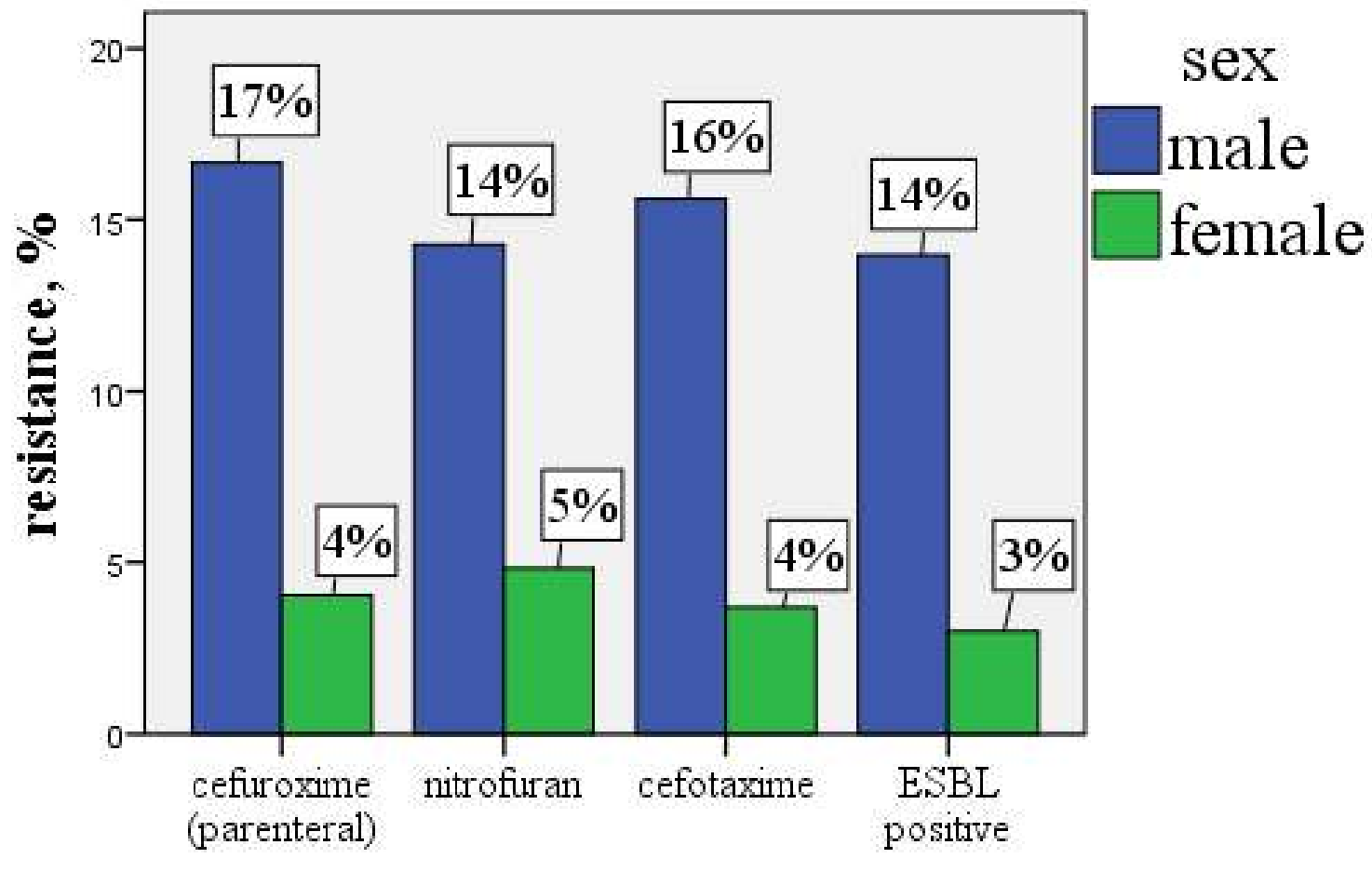

Table 2. Number of male and female patients in witch the specific antibacterial resistance was determined.

\begin{tabular}{|l|l|l|}
\hline Antibiotic & Male & Female \\
\hline Cefuroxime, $\mathrm{n}$ & 72 & 148 \\
\hline Nitrofuran, $\mathrm{n}$ & 112 & 228 \\
\hline Cefotaxime, $\mathrm{n}$ & 96 & 216 \\
\hline ESBL positive, $\mathrm{n}$ & 93 & 201 \\
\hline
\end{tabular}

ESBL - extended spectrum beta-lactamase 